\title{
Isotopic signatures of stratospheric air at the Himalayas and beyond
}

\author{
MANG LIN ${ }^{1}$, KUn WANG ${ }^{2}$, SHICHANG KANG ${ }^{2}$, YOUPING \\ $\mathrm{LI}^{3}$, ZHONGYU FAN ${ }^{3}$, MARK THIEMENS ${ }^{4}$ \\ ${ }^{1}$ State Key Laboratory of Isotope Geochemistry, Guangzhou \\ Institute of Geochemistry, Chinese Academy of Sciences \\ (CAS), Guangzhou China (linm@gig.ac.cn) \\ ${ }^{2}$ State Key Laboratory of Cryospheric Science, Northwest \\ Institute of Eco-Environment and Resources, CAS, \\ Lanzhou, China \\ ${ }^{3}$ College of Environmental Science and Engineering, China \\ West Normal University, Nanchong, China \\ ${ }^{4}$ Department of Chemistry and Biochemistry, University of \\ California San Diego, La Jolla, California, USA
}

Since the uplift of the Himalayas and Tibetan Plateau, this region has played an important role in the Asian monsoon system. The Himalayas are an important conduit for downward transport of stratospheric air to the troposphere, which significantly alters atmospheric chemistry and radiation budgets primarily by changing the tropospheric $\mathrm{O}_{3}$ budget. However, its intensity and potential influences on atmospheric chemistry at the Tibetan Plateau and surrounding regions remain poorly constrained due to the lack of conclusive observational evidence.

Here, we report notably higher concentrations of cosmogenic ${ }^{35} \mathrm{~S}$ (a stratospheric tracer, half-life: $\sim 87.4$ days) in atmospheric sulfates from Mount Everest and downwind in Southwest China than other mid-latitude sites. Box-model calculations and atmospheric reanalysis data indicate that this new finding is best explained by springtime stratospheric intrusions occurring at the Himalayas, which affect a larger geographic region than previously thought. In addition, triple oxygen isotopic anomalies of sulfates $\left(\Delta^{17} \mathrm{O}: 1.58-2.50 \%\right)$ observed in the same sulfate aerosol samples, especially those with high ${ }^{35} \mathrm{~S}$ activities, are higher than observed in East China (1.00-1.59\%). This observation implies a sulfate formation chemistry at the Himalayas and its downwind region significantly different from East China due to highaltitude air mass influences. We suggest that long-term variations of sulfate $\Delta^{17} \mathrm{O}$ values and other long-lived cosmogenic nuclide abundances in our study region, which are affected by their formation source altitudes, may be preserved in ice cores and relevant geological records, providing important paleo-climate and paleo-altimetry information of the world's highest plateau. 